\title{
A serological test for granuloma inguinale
}

\author{
A L Freinkel, Y Dangor, H J Koornhof, R C Ballard
}

\begin{abstract}
Objectives-An indirect immunofluorescence technique applied to paraffin

* embedded tissue sections of lesions containing Donovan bodies was evaluated as a serological test for the diagnosis of granuloma inguinale.

Methods-Sera from patients with proven granuloma inguinale, other sexually acquired genital ulcerations and blood donors from areas where granuloma inguinale is rarely encountered as well as from disease-endemic regions were tested. Sera were tested either unabsorbed or following absorption with whole Klebsiella pneumoniae bacteria.
\end{abstract}

Results-Using unabsorbed sera at a dilution of 1:160 the test was found to have a sensitivity of $100 \%$, specificity of $98 \%$, positive predictive value (PPV) of $89 \%$ and negative predictive value (NPV) of $100 \%$. There proved to be no advantage in preabsorbing sera with $K$. pneumoniae antigen.

Conclusions-In the absence of culture methods for Calymmatobacterium granulomatis, an indirect immunofluorescence technique may prove valuable for the diagnosis of individual cases of granuloma inguinale and as an epidemiological tool in studies of the disease.

\section{Introduction}

At present, establishment of a diagnosis of granuloma inguinale depends on a high degree of clinical suspicion of the disease and the demonstration of characteristic Donovan bodies in smears prepared from deep scrapings or punch biopsies of lesions, ${ }^{1}$ or in histological preparations of biopsy material. ${ }^{2}$ Since routine cultivation of the causative bacterium, Calymmatobacterium granulomatis, is at present not possible, a serological test for this disease may prove useful, not only for diagnosis, but also as an epidemiological tool in areas where the disease is suspected to occur.

In general, serological tests require the use of a suitable antigen which is normally obtained from cultures of the causative organism. In 1943 organisms resembling Donovan bodies were cultured in the yolk-sacs of eggs of freerange chickens. ${ }^{3}$ These organisms had previously been obtained by aspiration of material rich in Donovan bodies from unruptured pseudo-buboes. Antigen was subsequently prepared from such cultures and positive serological reactions were obtained in the majority of cases of granuloma inguinale when the antigen was used as a component of either precipitin or complement fixation tests. ${ }^{45}$ Unfortunately cultures of these organisms are no longer available and therefore this suitable source of antigen cannot be used.

During early studies on granuloma inguinale it was noted that an immunological relationship existed between some strains of $C$. granulomatis and Klebsiella pneumoniae. ${ }^{6}$ Maddox et al. in Papua-New Guinea, ${ }^{7}$ compared the serological reactions obtained when using a limited supply of $C$. granulomatis antigen with those obtained with an antigen prepared from a strain of $K$. pneumoniae. It was concluded that although less sensitive, the klebsiella antigen cross-reacted with antibody to $C$. granulomatis sufficiently to be useful in the serological diagnosis of granuloma inguinale.

During studies on the aetiology of genital ulcer disease undertaken in southern Africa it was noted that large numbers of Donovan bodies were often present in tissue sections prepared from lesions of granuloma inguinale. ${ }^{18}$ It therefore seemed logical that the bodies present in these sections could be used as a source of antigen in an indirect immunofluorescence test. In this study, we have attempted to determine the sensitivity and specificity of the technique in an area where the disease is known to occur. In addition, the effect of absorption of sera with $K$. pneumoniae antigens on the sensitivity and specificity of the test was investigated.

\section{Patients and methods}

Sera were obtained from 55 cases of microscopically-proven granuloma inguinale seen either at the Leslie Williams' Memorial Hospital, Carletonville, Transvaal, or various hospitals in the Eastern Transvaal and Swaziland. In addition 289 sera were obtained from patients with sexually acquired genital ulcer disease (GUD) other than granuloma inguinale (mainly chancroid) during an ongoing surveillance programme on GUD undertaken at the Leslie Williams' Memorial Hospital, Carletonville. 9 A further 79 sera were obtained from presumably healthy blood donors on the Witwatersrand (where granuloma inguinale is infrequently seen) and 413 sera were also collected from blood donors in areas of South Africa (Eastern Transvaal and Natal) where clinical cases of granuloma inguinale have frequently been recorded. ${ }^{18}$

Fifty of the sera obtained from patients with proven granuloma inguinale were tested prior 


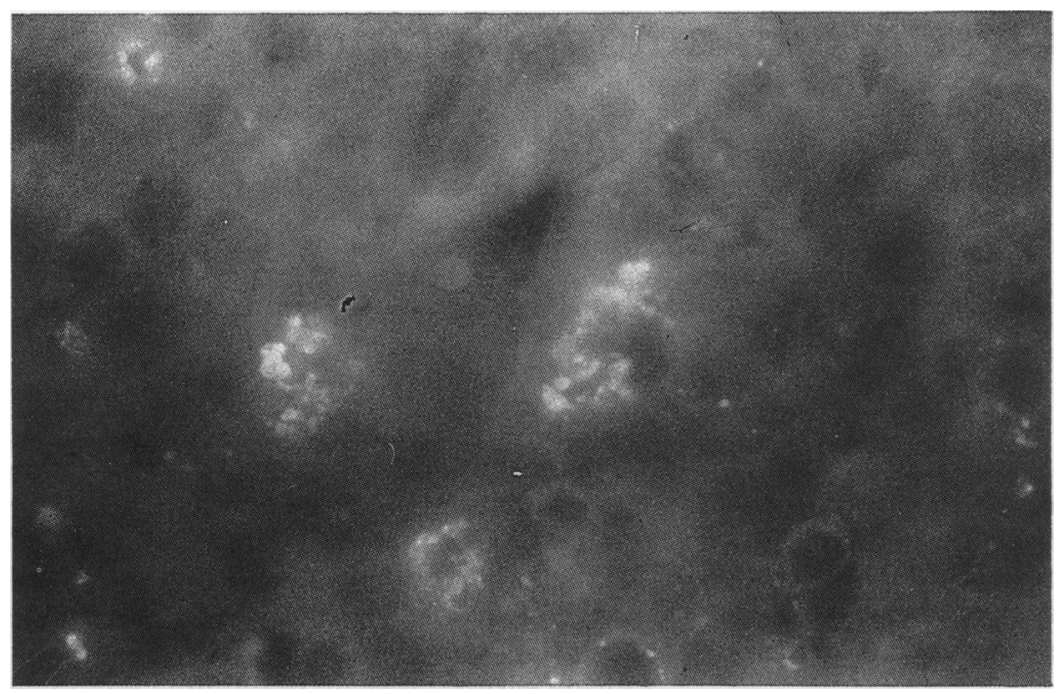

Fig Donovan bodies present in a lesion of granuloma inguinale appear as clusters of fluorescent oval bodies in a positive immunofluorescence test

to absorption with $K$. pneumoniae antigen and all 55 sera were tested following absorption. Of the remaining sera only those found to have significant titres $(>1: 160)$ were absorbed and retested.

The indirect immunofluorescence technique was performed by applying suitable dilutions of test serum to protease-treated, dewaxed and rehydrated tissue sections $(5 \mu \mathrm{m})$ cut from tissue obtained from a lesion clinically and histologically diagnosed as granuloma inguinale, and incubated at $37^{\circ} \mathrm{C}$ for 30 minutes. The sera were applied to a series of sections in doubling dilutions commencing with a dilution of $1: 20$. Both positive and negative control sections were used in each batch of sera tested. The sections were then incubated for a further $30 \mathrm{~min}$ at $37^{\circ} \mathrm{C}$ with sheep antihuman $\mathrm{IgG}$ conjugated with fluorescein isothiocyanate (Wellcome Diagnostics, Beckenham, Kent) counter-stained with Evans blue, mounted in an aqueous mounting medium, and examined at $\times \mathbf{4 0 0}$ magnification by means of a fluorescence microscope. A positive reaction was defined as clusters of bright fluorescing oval structures of about $1.5 \mu \mathrm{m}$ within vacuoles in large mononuclear cells (fig). The highest dilution of serum which produced typical fluorescence was regarded as the titre of the serum under consideration.

The test was found to be reproducible, with titres obtained following retesting deviating by a maximum of one dilution. The test was later modified to include absorption of cross reacting antibodies from the sera by the use of a strain of $K$. pneumoniae in a procedure similar to the absorption of nonspecific treponemal antibodies from sera, as described by Wood et $a^{10}{ }^{10} \mathrm{~K}$. pneumoniae strain ATCC 13883 was grown in BHI broth overnight at $37^{\circ} \mathrm{C}$, subcultured on agar, washed with phosphate buffered saline ( $\mathrm{pH} 7 \cdot 2)$ and centrifuged to form firm pellets. Patient's serum $(0.5 \mathrm{ml})$ was added to $0.2 \mathrm{ml}$ of pellet material, mixed, then recentrifuged to form a pellet and the supernatant serum used in the fluorescent antibody test.

The clinical performance of the serological test was evaluated by applying the predictive value model as described by Galen. ${ }^{11}$

\section{Results}

Prior to absorption, all the sera obtained from patients with granuloma inguinale reacted positively at titres $>1: 160$ (See table 1 ). But at titres $>1: 160$, there were eight sera from presumably healthy blood donors and six sera from patients with a sexually transmitted disease other than granuloma inguinale whose sera were found to be reactive.

After absorption with $K$. pneumoniae antigen all except two sera obtained from confirmed cases of granuloma inguinale remained reactive but at lower titres which varied from 1:10 to 1:1280 (table 2). None of the blood transfusion sera from the Witwatersrand were found to be reactive following absorption but 11 sera obtained from disease-endemic areas remained reactive (titres ranged 1:10-1:320) and one serum obtained from an STD patient with proven chancroid was also reactive at a titre of $1: 20$.

The sensitivity, specificity, positive and negative predictive values and efficiency of the test, with both unabsorbed and absorbed sera and using the GUD sera as negative controls are shown in table 3.

The efficiency of the test was not enhanced as a result of inclusion of the absorption step. Clearly, the results with the sera obtained from blood donors confirm the clinical impression that granuloma inguinale is not endemic on the Witwatersrand but occurs in the eastern Transvaal and Natal.

Table 1 Distribution of immunofluorescence antibody titres toDonovan bodies in sera from patients with granuloma inguinale, other genital ulcer diseases and blood donors (unabsorbed)

\begin{tabular}{|c|c|c|c|c|}
\hline \multirow[b]{2}{*}{ Titre } & \multirow[b]{2}{*}{$\begin{array}{l}\text { Proven } \\
\text { Granuloma inguinale }\end{array}$} & \multirow[b]{2}{*}{$\begin{array}{l}\text { STD } \\
\text { sera }\end{array}$} & \multicolumn{2}{|c|}{ Blood Donor Sera } \\
\hline & & & $\begin{array}{l}\text { Witwatersrand } \\
\text { (non-endemic) }\end{array}$ & $\begin{array}{l}\text { E.Tvl/Natal } \\
\text { (endemic) }\end{array}$ \\
\hline $\begin{array}{l}1: 5120 \\
1: 2560 \\
1: 1280 \\
1: 640 \\
1: 320 \\
1: 160 \\
1: 80 \\
1: 40 \\
1: 20 \\
\text { Neg } \\
\text { Total }\end{array}$ & $\begin{array}{r}3 \\
6 \\
8 \\
17 \\
10 \\
6 \\
- \\
- \\
- \\
50\end{array}$ & $\begin{array}{r}- \\
= \\
- \\
1 \\
5 \\
9 \\
2 \\
1 \\
271 \\
289\end{array}$ & $\begin{array}{l}z \\
\overline{-} \\
\overline{-} \\
\overline{1} \\
4 \\
9 \\
65 \\
79\end{array}$ & $\begin{array}{r}1 \\
-\quad 1 \\
- \\
- \\
6 \\
7 \\
18 \\
66 \\
316 \\
413\end{array}$ \\
\hline
\end{tabular}


Table 2 Distribution of immunofluorescence antibody titres to Donovan bodies in sera from patients with granuloma inguinale, other genital ulcer diseases and blood donors (sera absorbed with K. pneumoniae antigen)

\begin{tabular}{|c|c|c|c|c|}
\hline \multirow[b]{2}{*}{ Titre } & \multirow[b]{2}{*}{$\begin{array}{l}\text { Proven } \\
\text { Granuloma inguinale }\end{array}$} & \multirow[b]{2}{*}{$\begin{array}{l}\text { STD } \\
\text { sera }\end{array}$} & \multicolumn{2}{|c|}{ Blood Donor Sera } \\
\hline & & & $\begin{array}{l}\text { Witwatersrand } \\
\text { (non-endemic) }\end{array}$ & $\begin{array}{l}\text { E.Tvl/Natal } \\
\text { (endemic) }\end{array}$ \\
\hline $\begin{array}{l}1: 1280 \\
1: 640 \\
1: 320 \\
1: 160 \\
1: 80 \\
1: 40 \\
1: 20 \\
1: 10 \\
\text { Neg } \\
\text { Total }\end{array}$ & $\begin{array}{r}1 \\
5 \\
5 \\
7 \\
8 \\
3 \\
21 \\
3 \\
2 \\
55\end{array}$ & $\begin{array}{l}- \\
- \\
- \\
- \\
- \\
1 \\
\overline{288} \\
289\end{array}$ & $\begin{array}{l}- \\
- \\
- \\
- \\
- \\
\bar{z} \\
79 \\
79\end{array}$ & $\begin{array}{r}- \\
-1 \\
1 \\
1 \\
1 \\
3 \\
4 \\
402 \\
413\end{array}$ \\
\hline
\end{tabular}

Table 3 Characteristics of the indirect immunofluorescence test for antibody to Donovan bodies

\begin{tabular}{llllll}
\hline & Sensitivity (\%) & Specificity (\%) & PPV (\%) & NPV(\%) & Efficiency (\%) \\
\hline Unabsorbed $(>1: 160)$ & 100 & 98 & 89 & 100 & 98 \\
Unabsorbed $(>1: 320)$ & 88 & 100 & 98 & 99 & \\
Absorbed & 96 & 100 & 98 & 99 & \\
\hline
\end{tabular}

PPV $=$ Positive predictive value. $\mathrm{NPV}=$ Negative predictive value

\section{Discussion}

The results of these preliminary studies clearly indicate that de-waxed tissue sections from proven cases of granuloma inguinale can be successfully used as an antigen in indirect immunofluorescence tests to detect antibody to $C$. granulomatis. In its original form, with no absorption step, the test clearly differentiated between cases of granuloma inguinale and other causes of genital ulcer disease such as chancroid, syphilis, lymphogranuloma venereum and genital herpes which also occur on the subcontinent. No advantage was gained by including a relatively complicated absorption step using $K$. pneumoniae antigens designed to increase the specificity of the test. However, break-point titres had to be employed in unabsorbed tests in order to achieve satisfactory levels of sensitivity and specificity. If all sera exhibiting antibody titres $>1: 160$ were considered positive the sensitivity was found to be $100 \%$ and therefore this could be used as an ideal dilution of serum to screen if granuloma inguinale was being excluded as a diagnosis (NPV $=100 \%$ ). Likewise titres of $>1: 320$ were found to be $100 \%$ specific for granuloma inguinale with a PPV of $98 \%$. In practice this could be used as the antibody titre which would be considered diagnostic for the disease.

In this study, the calculations of the characteristics of accuracy of the serological test were made using sera obtained from migrant mineworkers with other proven causes of genital ulceration as negative controls. Approximately $60 \%$ of these patients usually live in areas where granuloma inguinale is thought to be endemic but the remainder come from areas remote from the "endemic region". It could be argued that this group of patients may not be an ideal negative control group for the test; however, their inclusion does indicate that antibody to other causes of genital ulceration does not cross-react in the granuloma inguinale antibody test. Ideally a similar group of STD patients drawn exclusively from granulo- ma inguinale-endemic areas should be used as the negative control group in order to determine more accurately the specificity of the test.

The patterns of reactivity of the blood donor sera obtained from both endemic and nonendemic areas indicate that exposure to $C$. granulomatis or a closely related organism occurs more frequently in granuloma inguinale-endemic areas. The reactivity detected in sera obtained in the endemic area could reflect either non-specific reactivity, detection of latent or undisclosed disease or previously treated infection. Absorption of the sera with $K$. pneumoniae antigen resulted in lowering of titres in individual cases but the fact that sera remained reactive in the modified (absorbed) test indicates that the reactivity is unlikely to be non-specific.

In this study, we were unable to establish a relationship between duration of infection and presence of elevated antibody levels. In early disease serum antibody may not be detectable, which could limit the diagnostic usefulness of the test. Likewise, further studies on the persistence of antibody to $C$. granulomatis following successful therapy for the disease are clearly indicated. Until $C$. granulomatis organisms can be cultivated in pure culture this serological test could be used to screen relatively large numbers of sera in order to determine whether granuloma inguinale constitutes a significant public health problem in a particular area.

By adapting the test using a known positive serum, the indirect immunofluorescence staining technique could also provide an additional, novel and specific method for demonstrating Donovan bodies in tissue sections or smears obtained from cases of the disease.

1 Freinkel AL. Granuloma inguinale (Donovanosis). Southern African fournal of Sexually Transmitted Diseases African Fourna

2 Freinkel AL. Histological aspects of sexually transmitted genital lesions. Histopathology 1987;11:819-31. 
3 Anderson $\mathrm{K}$. The cultivation from granuloma inguinale of a microorganism having the characteristics of Donova bodies in the yolk sac of chick embryos. Science 1943;97: $560-1$.

4 Anderson K, Goodpasture EW, deMonbreun WA. Immunologic relationship of Donovania granulomatis to granuloma inguinale. $\mathcal{E} \operatorname{Exp}$ Med 1945;81:41-51.

5 Goldberg J, Weaver RH, Packer H, Simpson WG. Studies on granuloma inguinale II The complement fixation test in the diagnosis of granuloma inguinale. American fournal of Syphilis, Gonorrhea and Venereal Diseases 1953;37:71-6.

6 Packer H, Goldberg J. Studies of the antigenic relationship of $D$. granulomatis to members of the tribe eschericheae. of D. granulomatis to members of the tribe eschericheae.
American fournal of Syphilis, Gonorrhea and Venereal American fournal of Syph

7 Maddocks I, Anders EM, Dennis E. Donovanosis in Papua New Guinea. Br $\mathcal{Y}$ Venereal Dis 1976;52:190-6.
8 Freinkel AL. Granuloma inguinale of cervical lymph nodes simulating tuberculous lymphadenitis: two case reports and review of published reports. Genitorin Med 1988;64:339-43.

9 Dangor Y, Fehler G, Exposto F da L MPP, Koornhof HJ. Causes and treatment of sexually acquired genital ulceration in southern Africa. $S$ Afr Med fै 1989;76:339-41.

10 Wood RM, Inouye Y, Argonza W, Bradford L, Jue R, Jeong Y, Puffer J, Bodily HL. Comparison of the fluorescent treponemal antibody absorption and Treponema pallidum immobilisation tests on serums from 1182 diagnostic problem cases. Am $\mathcal{F}$ Clin Pathol 1967;47:521-4.

11 Galen RS. Use of predictive value theory in clinical immunology. In: Rose NR, Friedman H, Fahey JL, eds. immunology. In: Rose NR, Friedman H, Fahey JL, eds. ington, American Society for Microbiology, 1986 966-970. 